\title{
Effect of Transverse Crack on Chloride Penetration into Concrete Subjected to Drying-Wetting Cycles
}

\author{
C. H. Lu, Y. Gao, and R. G. Liu \\ Department of Civil Engineering, Jiangsu University
}

\begin{abstract}
In this paper, several transversely cracked RC beams, self-anchored in a three-point bending mode, were prepared and subjected to $\mathrm{NaCl}$ solution drying-wetting cycles. Based on two experimental results obtained after 15 and 30 cycles, respectively, the profiles of free chloride concentration at different sections of sound and cracked concretes were presented and analyzed. The depth of surface convection zone in cracked concretes subject to chloride drying-wetting cycles is about 10-20 mm, which may increase gradually with the increasing of crack width. Then, it can be found that the speed of chloride penetration in concrete will be increased by cracks. Based on the equivalent diffusion model proposed in this paper, the apparent chloride diffusion coefficients for all sound and cracked sections were calculated. It can be found from the fitting precision that the equivalent diffusion model is suitable for analyzing the chloride penetration in flexural cracked concrete when its surface crack width is less than $0.3 \mathrm{~mm}$. Furthermore, the relationship between crack width and equivalent diffusion coefficient can be described with quadratic function of crack effect.
\end{abstract}

\section{INTRODUCTION}

Chloride-induced corrosion of reinforcing bar is one of the major causes for the deterioration of concrete structures in marine environment or subjected to deicing salts. To predict the service life of such structures, it is necessary to quantify the chloride penetration process in structural concrete. It is clearly known that the chloride transport properties of concrete (notably, permeability, and diffusion) will be influenced by its characteristics, such as existence of cracks, environmental exposure conditions, concrete quality, and so on (Win, Watanabe, \& Machida, 2004). Commonly, loadinduced cracks frequently appear in reinforced concrete (RC) structures in service. These cracks can accelerate chloride penetration and water permeation, and as a result they may reduce the service life of RC structures exposed to chloride attack (Djerbi, Bonnet, Khelidj, \& Baroghel-Bouny, 2008). For the environmental conditions of marine structures, except for temperature, $\mathrm{RH}$, and chloride ion concentration, it is widely accepted that the zone suffering from seawater drying-wetting cycles is the most dangerous part for steel corrosion and it has been regarded as the chief factor in the durability design (DuraCrete, 2000). Therefore, it is worthwhile to study the mechanism of chloride penetration in flexural cracked structural concrete under chloride drying-wetting cycles condition.

The aim of this paper is to investigate the effect of flexural crack induced by loads on chloride penetration into structural concrete with drying-wetting cycles. Based on the experimental results, the work to validate the applicability of Fick's second law in describing the chloride profile in cracked concrete has been completed. Then, the relationship between equivalent chloride diffusion coefficient and crack with has been obtained and simplified.

\section{MODELING OF CHLORIDE TRANSPORT IN SOUND CONCRETE WITH DRYING-WETTING CYCLES}

For concrete suffering from seawater drying-wetting cycles, the chloride transport in concrete is a typical process of chloride penetration in nonsaturated concrete. And it is assumed that the chloride ingress process is a combination of diffusion and convection. Chlorides in cementitious materials usually have free and bound components, and only free chlorides can transport in concrete. Thus, the partial differential equation, which governs the chloride diffusion in partially saturated concrete, can be given as (Ababneh, Benboudjema, \& Xi, 2003):

$$
\frac{\partial C_{t}}{\partial t}=\frac{\partial C_{t}}{\partial C_{f}} \frac{\partial C_{f}}{\partial t}=\nabla\left[D_{C l} \operatorname{grad}\left(C_{f}\right)\right]+\mu \frac{\partial w}{\partial t} C_{f}
$$

where $C_{t}$ and $C_{f}$ are total and free chloride concentration (\%wt. of concrete); $D_{\mathrm{cl}}$ is the chloride diffusion coefficient $\left(\mathrm{m}^{2} / \mathrm{s}\right) ; w$ is the mass of water 
per unit volume of concrete; $\mu$ is a unit conversion factor for converting the unit of the second term in the right-hand side of Equation (1) to grams of chloride per gram of concrete $\mu=1 /\left(\rho_{\text {sol }} \beta_{\text {sol }}\right)$, where $\rho_{\text {sol }}$ is the density of pore solution in grams of pore solution per liter; $\beta_{\text {sol }}$ is the ratio of volume of pore solution to weight of concrete.

Many results obtained from field inspections and lab tests indicate that, under the chloride solution cyclic drying-wetting condition, the action of convection [the second term in the right-hand side of Equation (1)] mainly occurs in the surface zone of concrete, where the convection depth $\Delta x$ is generally in the range of 5-15 mm (Ye, Jin, Jin, \& Fu, 2012). Thus, for the inner concrete starting from the end of surface convention zone, diffusion is the dominant mechanism to drive chloride transport in concrete. To simply the model and apply it into practical application pragmatically, the most commonly used equation called Fick's second law equation is modified taking consideration of the influence of convection zone. Its one-dimensional diffusion model can be generated from Equation (1) as:

$$
\frac{\partial C_{t}}{\partial C_{f}} \frac{\partial C_{f}}{\partial t}=\frac{\partial}{\partial x^{\prime}}\left[D_{C l} \frac{\partial C_{f}}{\partial x^{\prime}}\right] \quad\left(x^{\prime}=x-\Delta x\right)
$$

Let $C_{\mathrm{b}}$ denote the bound chloride concentration. Some experimental results found that there was a liner relationship between bound chlorides and free chloride (Ishida, Iqbal, \& Anh, 2009; Mohammed \& Hamada, 2003), which can be expressed with $C_{\mathrm{b}}=R \cdot C_{\mathrm{f}}$. Here, $R$ is a parameter and can be obtained from experiments. Then the partial derivative $\partial C_{t} / \partial C_{f}$ in Equation (2) can be simplified as:

$$
\frac{\partial C_{t}}{\partial C_{f}}=\frac{\partial\left(C_{f}+C_{b}\right)}{\partial C_{f}}=1+\frac{d C_{b}}{d C_{f}}=1+R
$$

Assuming the surface chloride concentration is constant and initial chloride content in concrete is 0 , the free chloride concentration profile can be expressed as Equation (4) using error function (erf):

$$
C_{\mathrm{f}}(x, t)=C_{\mathrm{s}, \Delta x}\left[1-\operatorname{erf}\left(\frac{x-\Delta x}{2 \sqrt{(1+R)^{-1} D_{\mathrm{a}} t}}\right)\right]
$$

where $C_{f}(x, t)$ is the free chloride concentration at a depth $x(x>\Delta x)$ and exposure time $t(s) ; \Delta x$ is the depth of surface convention zone $(\mathrm{mm}) ; C_{\mathrm{s}, \Delta x}$ is the surface chloride concentration at depth $\Delta x(\%) ; D_{\mathrm{a}}$ is the apparent chloride diffusion coefficient $\left(\mathrm{m}^{2} / \mathrm{s}\right)$, which is obtained by fitting the chloride profiles in a given period $t$.

\section{EQUIVALENT CHLORIDE DIFFUSION IN CRACKED CONCRETE WITH DRYING-WETTING CYCLES}

Under service condition, concrete structures always have cracks. Effects of cracks on the chloride diffusion and permeation in concrete have been investigated by many researchers. Kwon, Na, Park, and Jung (2009) considered that crack width could be only regarded as a governing parameter in deriving the function of diffusion coefficient in cracked concrete. Based on the results got from field investigations, a calculation model of apparent chloride diffusion coefficient in the early cracked concrete was proposed by simply considering the effect of crack width, shown in Equation (5). Park, Kwon, and Jung (2012) evaluated the crack effect on chloride diffusion in splitting cylinder concrete by nonsteady-state migration test and proposed an analytical model of effective diffusion coefficient in cracked concrete, given by Equation (6). Djerbi et al. (2008) examined the effects of traversing cracks of splitting cylinder concrete using a steady-state migration test and found the diffusion coefficient increased with the increasing crack width. The ratio of diffusion coefficient in cracked and sound concrete, $D(w) / D$, is plotted in Figure 1. Meanwhile, the relationship curves of $D(w) / D$ and $w$ given in Equations (5) and (6) are also given in Figure 1. It should be noted that the meanings of the chloride diffusion coefficient in above tests are different, but the ratio of corresponding diffusion coefficient in cracked and sound concrete are comparable.

$$
\begin{gathered}
D_{\mathrm{a}}(w)=\left(31.61 w^{2}+4.73 w+1\right) \cdot D_{\mathrm{a}}(w \geq 0.1 \mathrm{~mm}) \\
D_{\mathrm{Cl}}(w)=\left(4189.27 w^{3}-1642.57 w^{2}+347.85 w+1\right) \cdot D_{\mathrm{Cl}}(6)
\end{gathered}
$$

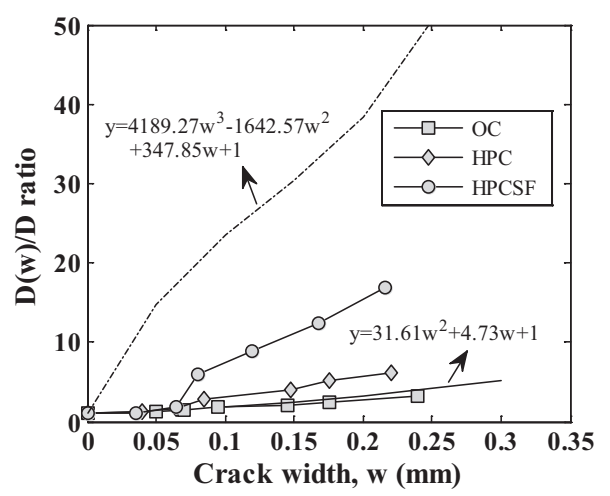

Figure 1. Relationship between $D(\mathrm{w}) / D$ ratio and $w$.

It can be seen from Figure 1 that the ratios of $D(w) / D$ obtained from different experiments show 
the similar tendency and all increase with the increase of $w$. These results indicate the chloride diffusion coefficient in cracked concrete has a close relationship with crack width. And this relationship will be affected by the crack type, material composition and test method of cracked members. Hence, for the transverse cracking concrete members, it is triable to use Fick's second law to describe chloride profiles in cracked concrete using 'equivalent apparent chloride diffusion coefficient, $D_{\text {eq }}$ ' instead of $D_{a}$ in Equation (4) (Gowripalan, Sirivivatnanon, \& Lim, 2000). Furthermore, according to regressive results as shown in Kwon et al. (2009) and Park et al. (2012), the relationship between $D_{\text {eq }}$ and $D_{\mathrm{a}}$ can be given as follows:

$$
D_{e q}=f(w) \cdot D_{a}
$$

where $f(w)$ is the crack effect function of diffusion coefficient in cracked concrete, which will be attempted to discuss and obtain in this article.

\section{EXPERIMENTAL PROGRAM}

\subsection{Mix proportion and preparation of specimens}

Concrete ingredients used were 42.5 ordinary Portland cement, with 5-25 mm crushed stone, natural sand with fineness modulus of 1.62 and tap water. The mix proportion is listed in Table 1. The 28-day compressive strength, as measured on standard $150 \mathrm{~mm}$ cubes, was $31.8 \mathrm{MPa}$.

Table 1. Mix proportion of concrete.

\begin{tabular}{cccccc}
\hline No. & W/C & $\begin{array}{c}\text { Water } \\
\left(\mathbf{k g} / \mathbf{m}^{3}\right)\end{array}$ & $\begin{array}{c}\text { Cement } \\
\left(\mathbf{k g} / \mathbf{m}^{3}\right)\end{array}$ & $\begin{array}{c}\text { Sand } \\
\left(\mathbf{k g} / \mathbf{m}^{3}\right)\end{array}$ & $\begin{array}{c}\text { Stone } \\
\left(\mathbf{k g} / \mathbf{m}^{3}\right)\end{array}$ \\
\hline OC & 0.43 & 185 & 430 & 560 & 1250 \\
\hline
\end{tabular}

Seven beam specimens of $150 \mathrm{~mm} \times 180 \mathrm{~mm} \times$ $1000 \mathrm{~mm}$ were reinforced with $2 \times \varphi 16 \mathrm{~mm}$ HRB 335 bars at the tension side with cover thickness of $30 \mathrm{~mm}$. All of the mixing and casting works were carried out in a standard laboratory. After demolding, the beams were moist-cured for the first 7 days and then natural-cured for next 21 days. After that, two specimens were self-anchored mutually and loaded with different cracking levels in a threepoint bending mode by tightening the screws, as shown in Figure 2. One or several transverse cracks appeared in the middle of the beam with a span of $400 \mathrm{~mm}$. After the loads became stable, the crack width at tension surface was measured using BJQF-A crack testing apparatus. All crack widths are shown in Table 2 and their visible crack lengths ranged from 60 to $120 \mathrm{~mm}$.

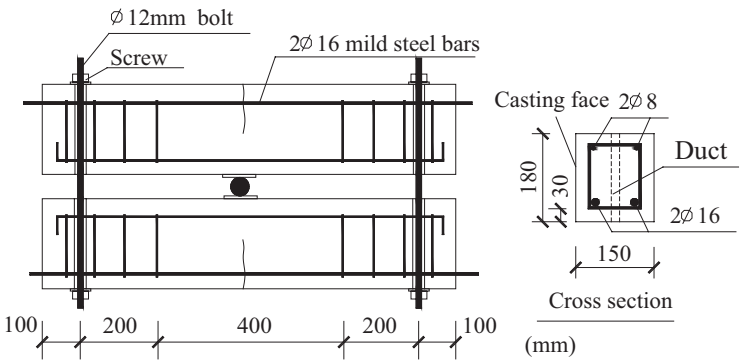

Figure 2. Schematic diagram of specimens under sustained loads.

Table 2. Crack width of testing beams.

\begin{tabular}{|c|c|c|}
\hline No. & Surface crack width $w(\mathrm{~mm})$ & Loading way \\
\hline OC-00 & - & No loads \\
\hline OC-01-1 & (1) 0.125 & \multirow{2}{*}{ Self-anchored } \\
\hline OC-01-2 & (1) 0.048 & \\
\hline OC-02-1 & (1) 0.286 ; (2) $0.243 ;$; 0.127 & \multirow[b]{2}{*}{ Self-anchored } \\
\hline OC-02-2 & (1) 0.326 ; (2) 0.268 ; (3) 0.135 & \\
\hline OC-04-1 & (1) 0.476 ; (2) 0.367 ; (3) 0.445 ; (4) 0.324 & \multirow{2}{*}{ Self-anchored } \\
\hline OC-04-2 & (1) 0.424 ; (2) 0.339 ; (3) $0.381 ;$ (4) 0.205 & \\
\hline
\end{tabular}

\subsection{Drying-wetting cycles experiment}

Just before cyclic drying-wetting testing, two side surfaces and the compression surface of all specimens were coated with epoxy resin to get the onedimensional transport of chloride. Then, all specimens were exposed to drying-wetting cycles with $5 \%$ by weight $\mathrm{NaCl}$ solution. The period of each cycle is 14 days with 7-day's wetting and 7-day's drying. Since it is difficult to monitor and adjust the crack width during the test and its duration is relatively short, the influence of anchor's relaxation and self-healing of concrete on crack width is neglected. All crack widths used were the initial crack widths just before exposure.

The determination of chloride content was made twice during the test. The first was done after 15 cycles and the tested specimens were the beams with the last number 1 . The second was carried out after 30 cycles (total 420 days) and the tested specimens were the beams with the last number 2 . Before sampling, the tested beams were removed from the $\mathrm{NaCl}$ solution pool, and placed in a dry place for a week. Then, the powder samples were obtained with a $16-\mathrm{mm}$ diameter drill at sound sections of the non-load specimens and cracked sections of cracking specimens (see Figure 3). At each section, powder samples were drilled along the depth direction, and the interval was $5 \mathrm{~mm}$ in the first depth of $20 \mathrm{~mm}$ and then became $10 \mathrm{~mm}$ within 20-60 mm. All powder samples were scrunched and passed through a $0.63-\mathrm{mm}$ sieve. Then, samples were put into a $105+5^{\circ} \mathrm{C}$ oven for $2 \mathrm{~h}$ and took out to cool down to room temperature. Each sample was divided into three groups and $1.5 \mathrm{~g}$ powder was weighed for 
each group. After distilled water extraction, the free chloride content of each group was determined using the standard rapid chloride testing (RCT). Finally, the mean of three groups was taken as the tested value.

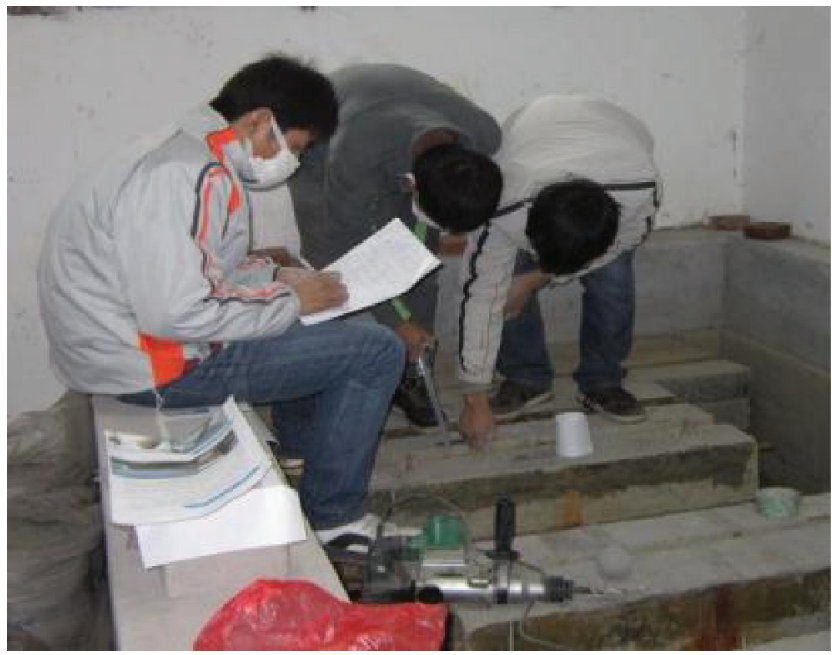

Figure 3. Sketch map of drilling powder.

\section{RESULT AND DISCUSSION}

\subsection{Free chloride ion content}

By calculation, the profiles of the free chloride ion content (\%wt. of concrete) at sound and cracked sections after 15 and 30 cycles were shown in Figures 4 and 5, respectively.

It can be seen from the Figures 4 and 5 that there is an increasing of chloride ion concentration within surface concrete for both sound and cracked sections. And there will appear a peak of chloride concentration in the surface convection zone. This phenomenon is caused by the periodic change of pore solution saturation in convection zone concrete under the condition of drying-wetting cycles. It can be obtained from the experimental results that there is some influence of crack width on the depth of convention zone $\Delta x$. It is estimated that $\Delta x$ locates in a range from approximately $10-15 \mathrm{~mm}$ with crack width less than $0.3 \mathrm{~mm}$, while about $20 \mathrm{~mm}$ with crack width $>0.3 \mathrm{~mm}$.

In the inner concrete with depth $>20 \mathrm{~mm}$, the results given in Figures 4 and 5 show that at same depth the free chloride ion content in cracked section is significantly higher than that in sound section. This indicates that the existence of transverse crack can accelerate the chloride ion penetration into concrete, which makes the risk of steel corrosion become higher in cracked concrete. Besides, experiment results also present the following characteristics: (1) for sound concrete, the profiles of chloride ion content in the depth ranging from 15 to $60 \mathrm{~mm}$ accord well with the distribution

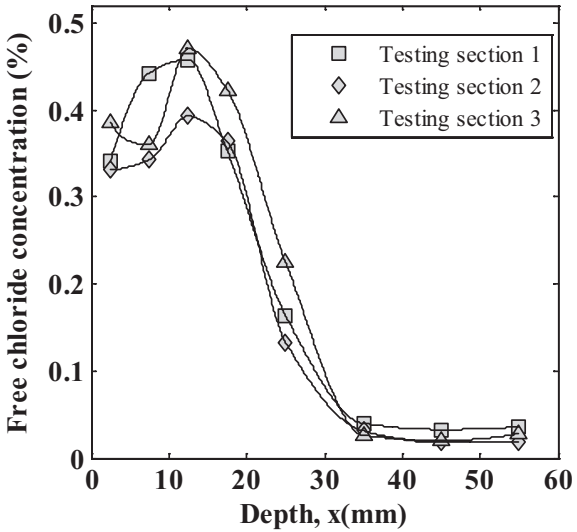

(a)

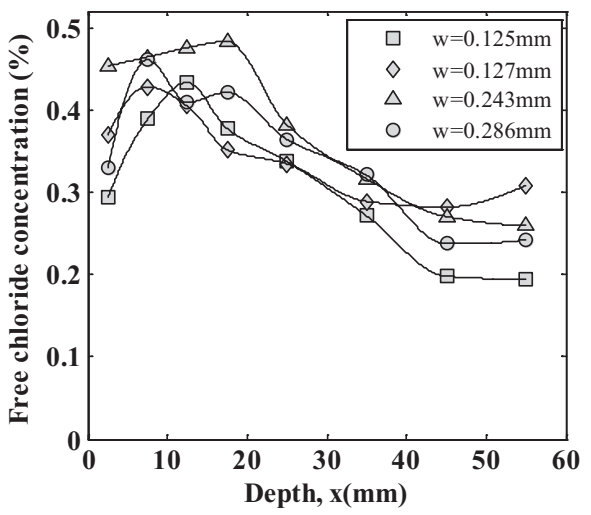

(b)

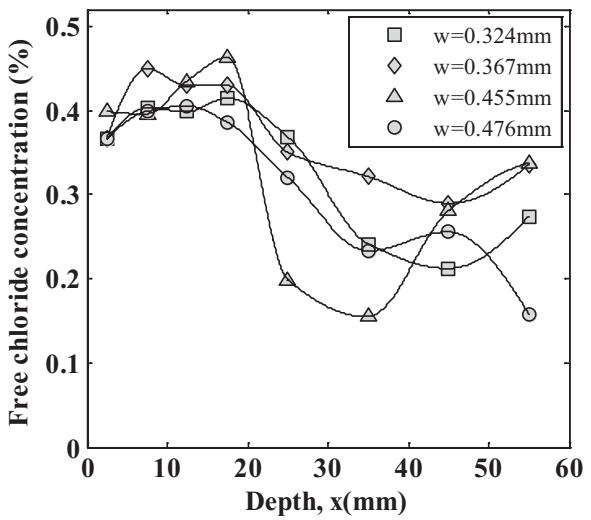

(c)

Figure 4. Free chloride ion concentration profiles at sound and cracked sections after 15 cycles. (a) Sound sections $(w=0)$. (b) Cracked sections with $w$ of $0.1-0.3 \mathrm{~mm}$. (c) Cracked sections with $w$ of $0.3-0.5 \mathrm{~mm}$.

curve of Fick's second law and can be matched by Equation (4); (2) for cracked concrete with crack width ranging from 0.05 to $0.3 \mathrm{~mm}$, the chloride content reduces with the increasing of depth gradually, but the decline of content becomes slow with the increasing of the crack width; (3) For cracked concrete with crack width $>0.3 \mathrm{~mm}$, the decline of chloride content with the increasing of depth is not obvious and even slight rise can be observed. Therefore, as for cracked concrete, 


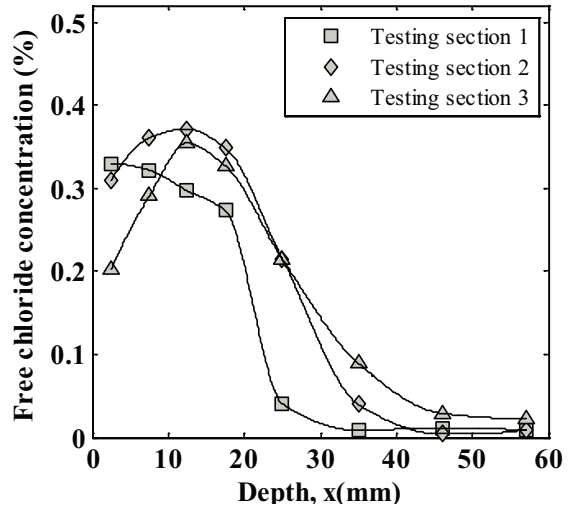

(a)

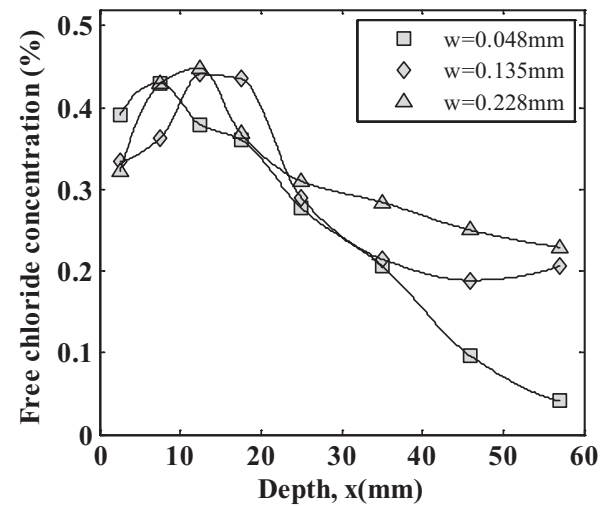

(b)

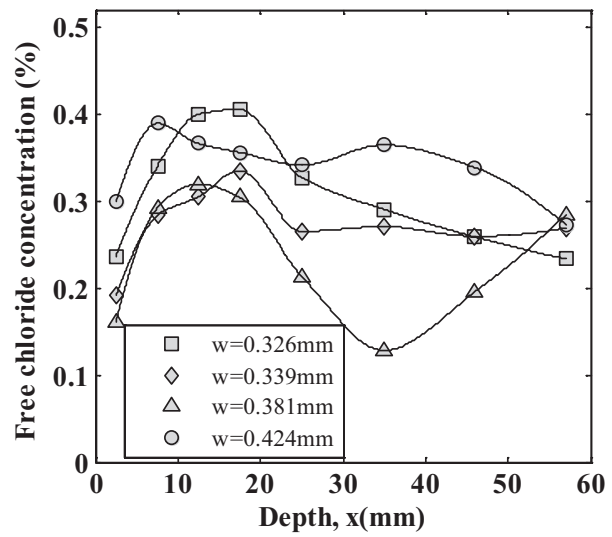

(c)

Figure 5. Free chloride ion concentration profiles at sound and cracked sections after 30 cycles. (a) Sound sections $(w=0)$. (b) Cracked sections with $w$ of $0.1-0.3 \mathrm{~mm}$. (c) Cracked sections with $w$ of $0.3-0.5 \mathrm{~mm}$.

it is necessary to further verify whether it is suitable to use Equation (4) to fit chloride profiles.

\subsection{Apparent chloride diffusion coefficient in sound concrete}

For sound concrete, the chloride profiles after 15 and 30 cycles were plotted in Figures 4(a) and 5(a), respectively. Here, only the contents within the depth ranging from 15 to $60 \mathrm{~mm}$ were adopted to be fitted by Equation (4) to get the apparent chloride diffusion coefficient $D_{\mathrm{a}}$. Before fitting, some parameters in Equation (4) are determined as follows: the value of parameter $R$ for ordinary Portland concrete was suggested to vary from 2 to 4 , and $R=2$ is used in this article. The surface chloride concentration at depth $\Delta x, \mathrm{C}_{\mathrm{s}, \Delta \mathrm{x}}$, is the concentration at the peak of convection zone, ranging from 0.3 to $0.5 \%$ wt. of concrete.

Using Matlab curve fitting toolbox, fitting analysis according to Equation (4) was performed and the results for sound concrete are shown in Table 3. The results shown in Table 3 indicate that the distribution of chloride content in inner concrete $(x>15 \mathrm{~mm})$ conforms well to the diffusion equation given in Equation (4) for sound concrete. The average of coefficient of determination $\left(R^{2}\right)$ which reflects fitting precision is $\sim 0.97$. Thus, it can be concluded that diffusion can be regarded as the main mechanism for chloride transport in inner concrete beyond convection zone when the concrete is subjected to drying-wetting cycles.

Table 3. Fitting results of apparent chloride diffusion coefficients at sound sections.

\begin{tabular}{lccc}
\hline Time & $\boldsymbol{D}_{\mathrm{a}}\left(\mathbf{\times 1 0 ^ { - 1 1 }} \mathbf{m}^{\mathbf{2}} / \mathbf{s}\right)$ & $\boldsymbol{C}_{\mathbf{s}}(\%)$ & $\boldsymbol{R}^{\mathbf{2}}$ \\
\hline 15 cycles & 1.968 & 0.466 & 0.9863 \\
& 1.973 & 0.424 & 0.9639 \\
& 2.412 & 0.504 & 0.9708 \\
\hline 30 cycles & 0.602 & 0.327 & 0.9313 \\
& 1.481 & 0.404 & 0.9668 \\
& 2.153 & 0.375 & 0.9859 \\
\hline
\end{tabular}

\subsection{Equivalent apparent chloride diffusion coefficient in cracked concrete}

For cracked concrete, the chloride profiles after 15 and 30 cycles were given in Figures $4(b, c)$ and $5(b, c)$, respectively. After curve fitting, the results of equivalent apparent chloride diffusion coefficient $D_{\text {eq }}$ were listed in Table 4. It can be observed from Table 4 that when the transverse crack width $w$ is $<0.3 \mathrm{~mm}$, the fitting precision $\left(R^{2}\right)$ is acceptable, which indicates that it is feasible to use equivalent diffusion Equation (4) to obtain $D_{\mathrm{eq}}$ in these cracked concrete. While for the sections with crack width larger than $0.35 \mathrm{~mm}$, the fitting precision seems to decline and become unsatisfactory, which shows the distribution of chloride concentration in these cracked sections does not conform to the Fick's second diffusion law. Therefore, it is not appropriate to use Equation (4) to get $D_{\text {eq }}$ when crack width exceeds $0.35 \mathrm{~mm}$, and these results are not listed in Table 4. The relationships between some test results and their fitting curves after 15 cycles are shown in Figure 6. 
Table 4. Fitting results of equivalent apparent chloride diffusion coefficient at cracked sections.

\begin{tabular}{|c|c|c|c|c|}
\hline Time & $w / m m$ & $D_{\text {eq }}\left(\times 10^{-11} \mathrm{~m}^{2} / \mathrm{s}\right)$ & $C_{\mathrm{s}}(\%)$ & $R^{2}$ \\
\hline \multirow[t]{6}{*}{15 cycles } & 0.125 & 26.18 & 0.419 & 0.9711 \\
\hline & 0.127 & 32.71 & 0.394 & 0.9234 \\
\hline & 0.243 & 36.66 & 0.480 & 0.9350 \\
\hline & 0.286 & 47.88 & 0.455 & 0.9559 \\
\hline & 0.324 & 32.15 & 0.428 & 0.9089 \\
\hline & 0.367 & 58.28 & 0.454 & 0.8522 \\
\hline \multirow[t]{6}{*}{30 cycles } & 0.048 & 4.713 & 0.399 & 0.9837 \\
\hline & 0.135 & 10.88 & 0.427 & 0.8317 \\
\hline & 0.205 & 30.91 & 0.404 & 0.9656 \\
\hline & 0.268 & 22.64 & 0.406 & 0.8779 \\
\hline & 0.326 & 27.53 & 0.401 & 0.9423 \\
\hline & 0.339 & 63.88 & 0.312 & 0.5834 \\
\hline
\end{tabular}

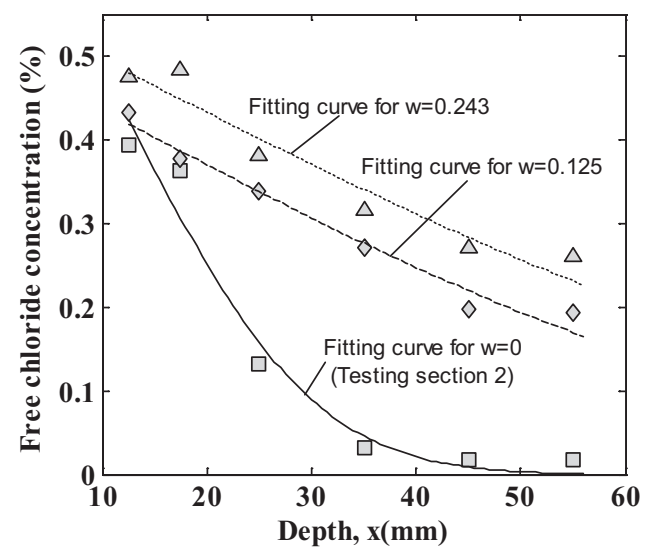

Figure 6. Relationship between tested chloride contents at typical sections and fitting curves (after 15 cycles).

\subsection{Determination of crack effect function $f(w)$}

From Table 3, the averages of apparent chloride diffusion coefficients $D_{a}$ for sound specimens after 15 and 30 cycles can be calculated to be $2.118 \times$ $10^{-11} \mathrm{~m}^{2} / \mathrm{s}$ and $1.412 \times 10^{-11} \mathrm{~m}^{2} / \mathrm{s}$, respectively. Based on Equation (7), the value of function $f(w)$ for certain crack width can be determined using $D_{\text {eq }}$ in Table 4 and the average of $D_{a}$, as shown in Figure 7. To get the relationship between crack effect function $f(w)$ and $w$, two different functions (quadratic and cubic function) were adopted to regression analysis. Finally, the regression formulas (see Equation (8)) were got and the relationship between test values and predicted values was also plotted in Figure 7. Besides, Figure 7 also gives the calculation results of the Equations (5) and (6) again for comparison.

$$
\begin{aligned}
f_{1}(w)= & 31.08 w^{2}+71.54 w+1, w<0.35 \mathrm{~mm} \\
f_{2}(w)= & 693.6 w^{3}-324.8 w^{2}+112.9 w \\
& +1, w<0.35 \mathrm{~mm}
\end{aligned}
$$

It can be concluded from Figure 7 that: (1) the regression results of quadratic and cubic functions can reflect the whole tendency of function $f(w)$ with the increase of crack width $w$, but the fitting precision is not good enough with the coefficient of determination nearly 0.74 . This may be the results of two sample regression analysis at the same time, which resulted in the increasing of the discreteness of test data. (2) Compared with the regression formulas given in the published reports (Kwon et al., 2009; Park et al., 2012) and test data (Djerbi et al., 2008), our results are greater than the values calculated by Equation (5) and less than the values calculated by Equation (6), and appropriate with the test results in Djerbi et al., 2008. Overall, the change tendency of the four is consistent. (3) Compared the fitting effect of Equation (8.1) with that of Equation (8.2), it is suggested to determine the crack effect function $f(w)$ with Equation (8.1) for practical engineering application.

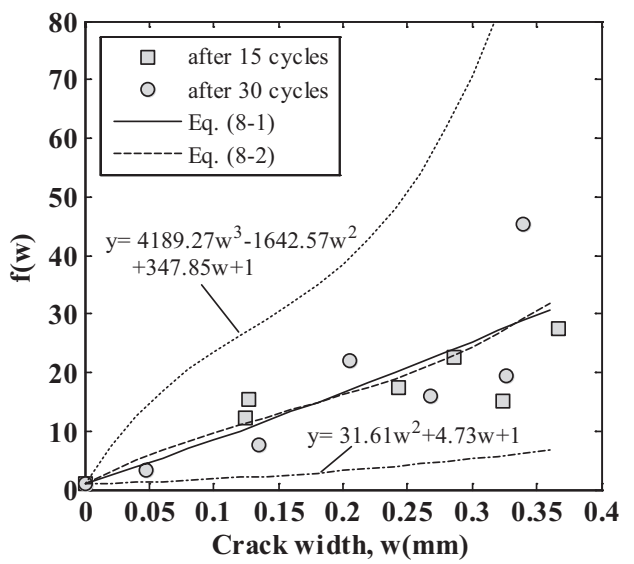

Figure 7. Relationship between regression curve of function $f(w)$ and experimental results.

\section{CONCLUSIONS}

Under the condition of seawater drying-wetting cycles, the chlorine diffusion model in sound concrete was established based on Fick's second law taking account of the effect of surface convection zone. The depth of convection zone is tested to be a range from approximately $10-15 \mathrm{~mm}$.

For cracked concrete with transverse crack width $<0.3 \mathrm{~mm}$, it is verified from experimental investigation that it is feasible to use equivalent chloride diffusion model to fit the chloride profile. And the crack effect on equivalent chloride diffusion coefficient can be simplified to be a quadratic function about crack width $w$.

\section{ACKNOWLEDGMENTS}

This work was financially supported by the National Natural Science Foundations of China (51378241 and 51278230), Specialized Research Fund 
for the Doctoral Program of Higher Education (20123227110006) and Fund for High Researcher of Jiangsu University (11JDG132).

\section{REFERENCES}

Ababneh, A., Benboudjema, F., \& Xi, Y. (2003). Chloride penetration in nonsaturated concrete. Journal of Materials in Civil Engineering, 15(2), 183-191.

Djerbi, A., Bonnet, S., Khelidj, A., \& Baroghel-Bouny, V. (2008). Influence of traversing crack on chloride diffusion into concrete. Cement and Concrete Research, 38(6), 877-883.

DuraCrete. (2000). European Union-Brite EuRam. General guide lines for durability design and redesign. DuraCrete, BE95-1347.

Gowripalan, N., Sirivivatnanon, V., \& Lim, C. C. (2000). Chloride diffusivity of concrete cracked inflexure. Cement and Concrete Research, 30(5), 725-730.

Ishida, T., Iqbal, P. O., \& Anh, H. T. L. (2009). Modeling of chloride diffusivity coupled with nonlinear binding capacity in sound and cracked concrete. Cement and Concrete Research, 39(10), 913-923.

Kwon, S. J., Na, U. J., Park, S. S., \& Jung, S. H. (2009). Service life prediction of concrete wharves with early-aged crack: Probabilistic approach for chloride diffusion. Structural Safety, 31(1), 75-83.

Mohammed, T. U., \& Hamada, H. (2003). Relationship between free chloride and total chloride contents in concrete. Cement and Concrete Research, 33(9), 1487-1490.

Park, S. S., Kwon, S. J., \& Jung, S. H. (2012). Analysis technique for chloride penetration in cracked concrete using equivalent diffusion and permeation. Construction and Building Materials, 29, 183-192.

Win, P. P., Watanabe, M., \& Machida, A. (2004). Penetration profile of chloride ion in cracked reinforced concrete. Cement and Concrete Research, 34(7), 1073-1079.

Ye, H., Jin, N., Jin, X., \& Fu, C. (2012). Model of chloride penetration into cracked concrete subject to drying-wetting cycles. Construction and Building Materials, 36(11), 259-269. 